\title{
The Relative Contributions of Mobile Sources to Air Pollutant Emissions in Tehran, Iran: an Emission Inventory Approach
}

\author{
Hossein Shahbazi $^{1} \cdot$ Masoud Reyhanian $^{1} \cdot$ Vahid Hosseini $^{1} \cdot$ Hossein Afshin $^{1}$
}

Received: 3 August 2015 /Revised: 8 December 2015 / Accepted: 14 December 2015 / Published online: 8 January 2016

(C) Springer International Publishing Switzerland 2016

\begin{abstract}
Tehran, a city with 8.5 million inhabitants, has suffered from rapid and unplanned urbanization in recent years resulting in substantial environmental impacts perhaps foremost of which is poor air quality. A major source of air pollution is emissions from mobile vehicles; therefore, having an accurate and comprehensive mobile source emission inventory is essential for decision-makers to develop mitigating strategies. The aim of this study is to determine the relative contributions of specific mobile sources to key air pollutants through the development of an emissions inventory for mobile sources in the city of Tehran using the International Vehicle Emissions (IVE) model. Tehran traffic data were acquired to obtain link level emission rates, using IVE emission rates. The developed emission inventory was evaluated using Tehran gasoline sales data. The results indicate that the sources of carbon monoxide $(\mathrm{CO})$, volatile organic compound (VOC), nitrogen oxide $\left(\mathrm{NO}_{x}\right)$, and sulfur oxide $\left(\mathrm{SO}_{x}\right)$ emissions are mainly passenger cars. The contribution of emissions of $\mathrm{CO}$, VOCs, and particulate matter (PM) from motorcycles to the total traffic emissions is more than 15,31 , and $12 \%$, respectively. Despite the fact that medium and heavy-duty vehicles (minibuses, buses, and trucks) only comprise $2.4 \%$ of the Tehran fleet, they contribute more than 41,64 , and $85 \%$ of the $\mathrm{NO}_{x}, \mathrm{SO}_{x}$, and $\mathrm{PM}$ emissions, respectively. Analyzing the distribution of the aggregated emission of pollutants shows that emissions are mostly higher in central zones due to the high traffic rate of passenger cars, taxis, motorcycles, and buses.
\end{abstract}

Vahid Hosseini

vhosseini@sharif.edu

1 Mechanical Engineering Department, Sharif University of Technology, Tehran, I.R. Iran
Keywords Emission inventory $\cdot$ IVE model $\cdot$ Emission reduction potentials $\cdot$ Tehran

\section{Introduction}

Air quality has become a major concern in developing countries such as Iran. Air pollution causes a growth in respiratory and cardiovascular illnesses and mortality. The economic burden of diseases from air pollution in Iranian mega-cities exceeds 8 billion dollars annually [1].

An accurate and comprehensive emission inventory helps governments to adopt effective strategies with regard to air pollution and enables them to plan costeffective strategies [2]. Furthermore, emission inventories are essential data for air quality forecasting models [3]. Vehicle technologies and population, industry types, manufacturing processes, and metropolitan infrastructure are changing constantly. Therefore, an emission inventory should be updated regularly in order to express current conditions [4].

This is since readers will understand that a large city in a developing country will have major problems from mobile source, and a proper inventory needs to be done. The emissions exhausted from mobile sources are the major sources of air pollution in urban areas [5]. Previous studies have used various emission inventory tools to calculate the mobile source emissions in urban areas. There are several methods for the calculation of vehicle exhaust emission factors [6]. Chassis dynamometer tests can be used for the measurement of emission factors under controlled conditions [7-9]. The portable emission measurement system (PEMS) is a well-known method which measures the exhaust emissions under real-world conditions 
[10-13]. Other methods for emission exhaust measurements are remote sensing [14] and tunnel studies [15].

Another economical and quick approach for calculating vehicle emissions is using emission models such as the motor vehicle emission simulator (MOVES), COPERT, and International Vehicle Emissions (IVE) models [16-18]. The MOVES model was developed by the U.S. Environmental Protection Agency (EPA) in order to estimate emissions for mobile sources covering a broad range of pollutants and allows multiple-scale analysis [19]. COPERT was developed by the European Environment Agency [20]. This model is widely used in Europe to calculate air pollutant and greenhouse gas emissions from road transport. [21-23]

The IVE model is another model for the calculation of average emission rates for different vehicle categories and facility types. The IVE model is specifically designed to have the flexibility needed by developing nations in their efforts to address mobile source emissions [24]. The IVE model has been applied in different countries worldwide, including China [24-26], India [27, 28], Vietnam [29], and Nepal [30]. The advantage of the IVE model is its sensitivity to existing vehicle technologies in developing countries and driving behavior quantified by vehicle-specific power and engine stress. These parameters have a significant influence on the vehicle exhaust emissions [25].

The emission inventory for Delhi, India, from 2003 to 2012 was calculated by the IVE model [27]. These results showed that the emissions of nitrogen oxide $\left(\mathrm{NO}_{x}\right)$, carbon monoxide (CO), and particulate matter (PM) increased between 2003 and 2012 by 69,46 , and $18 \%$, respectively.

The IVE model was used for developing the emission inventory in Kathmandu Valley, Nepal, for the mobile fleet consisting of buses, taxis, vans, motorcycles, and threewheelers (MC) during 2010 [30]. According to this result, most of the PM (93\%), $\mathrm{NO}_{x}(91 \%)$, and black carbon (99 \%) were emitted from buses, whereas motorcycles are the major source of $\mathrm{CO}$ and volatile organic compound (VOC) $(50 \%-79 \%)$.

Wang et al. calculated a mobile source emission inventory for Shanghai, China, using the IVE model [26]. They showed that cold starting is responsible for about $20 \%$ of total emissions. According to the model results, $36.3 \%$ of PM and $45 \%$ of VOC were emitted from motorcycles and mopeds, more than $50 \%$ of $\mathrm{PM}$ and $\mathrm{NO}_{x}$ were emitted from heavy-duty vehicles like buses and trucks, and the major source of the $\mathrm{CO}$ was light-duty vehicles.

Nesamani used IVE model in order to calculate emissions from vehicles in Chennai, India [31], with driving patterns collected using GPS. This calculation showed that over $60 \%$ of $\mathrm{NO}_{x}$ and $36 \%$ of PM emissions were from heavy-duty vehicles, while two- and three- wheelers were responsible for most of the $\mathrm{CO}$ emissions (about $64 \%$ ).

The only comprehensive Tehran emission inventory was developed by JICA in 1997 [32]. The mobile source emission accounted for $3 \%$ of sulfur oxide $\left(\mathrm{SO}_{x}\right), 29 \%$ of $\mathrm{NO}_{\mathrm{x}}, 70 \%$ of $\mathrm{HC}$, and $94 \%$ of $\mathrm{CO}$, and light-duty passenger cars were responsible for $58 \%$ of $\mathrm{CO}, 50 \%$ of $\mathrm{HC}, 14 \%$ of $\mathrm{SO}_{x}$, and $55 \%$ of $\mathrm{NO}_{x}$ emissions. Since then, despite major changes in fleet composition, vehicle technologies, vehicle population, emission standards implementation, and both gasoline and diesel fuel quality, the inventory has not been updated. It is clear that this emission inventory is currently inadequate for use in air quality models.

The aim of this study is to develop a link-based trafficrelated emission inventory of Tehran using a combination of traffic and emission rates modeling [33-36]. The Tehran traffic conditions were investigated comprehensively by the Tehran Comprehensive Transportation and Traffic Study (TCTTS) Company using modeling and measurement techniques. The Tehran traffic modeling data were obtained for the morning rush hour for emission estimation. IVE emission model was used to estimate the average fleet emission rates for different facility types and road grades. Hence, the total vehicle emissions, the share of each vehicle type in the total mobile source emissions, and the distribution of emissions in different areas of Tehran have been obtained. Also, temporal profiles were obtained based on traffic volume data counted at about 106 intersections over Tehran for the base year of 2013. Based on the detailed emission estimation, the impacts of fleet composition and fuel quality on pollution emissions were investigated.

\section{Study Area}

Tehran is the capital of Iran, with a population of more than 8.5 million in 2011. The annual mean temperature is $17{ }^{\circ} \mathrm{C}$, and the annual mean rainfall is about $230 \mathrm{~mm}$ [37]. The highest recorded temperature was $39{ }^{\circ} \mathrm{C}$, and the lowest recorded temperature was $-6{ }^{\circ} \mathrm{C}$ [38]. Tehran is the world's 19th largest city by population and one of the biggest cities of western Asia [39]. The city is located between $35^{\circ} 34^{\prime}$ and $35^{\circ} 50^{\prime}$ with a total area of more than $700 \mathrm{~km}^{2}$.

Air pollution is a major problem in Tehran [40] and has been influenced by several factors during recent years, including a rapid increase in population, high personal car ownership, and limited public transportation options [39]. As shown in Fig. 1, Tehran also has complex terrain conditions, which intensify the city's air pollution problem. The city is surrounded on the north 
Fig. 1 Tehran topology, surrounded by the Alborz Mountains on the north and east sides [41]
Topography height (meters MSL)

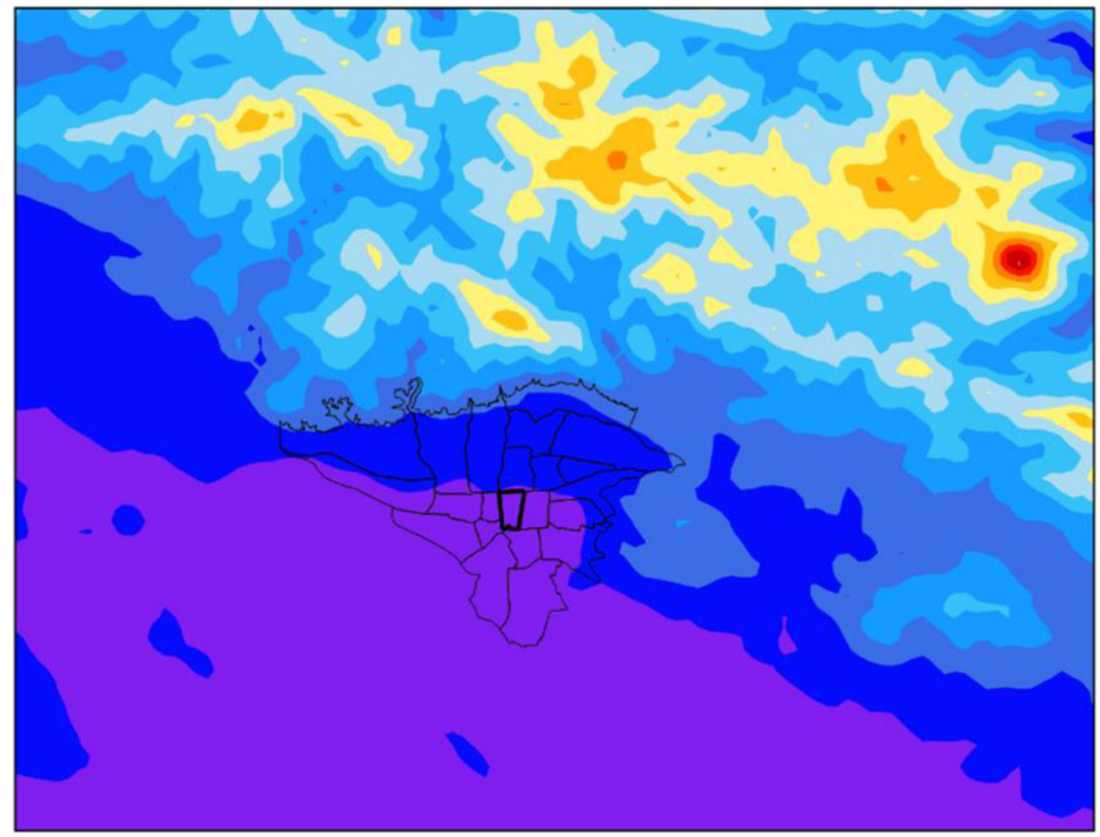

Topography height (meters MSL)

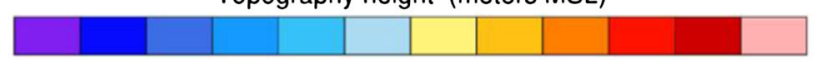

12001600200024002800320036004000440048005200

and northeast sides by the Alborz mountain range, which affects the winds on the east side of the city and the dispersion pattern of pollutants [38, 42].

\section{Methodology}

\subsection{Research Tools}

The emission estimation process in the IVE model is to multiply the base emission rate for each technology by a series of correction factors, which are defined for each vehicle technology, to estimate the adjusted emission rate from each vehicle type. The correction factors are categorized into local, fuel quality, and power and driving variables. Hence, by choosing different fuel configurations, different correction factors will be used for each vehicle technology.

In order to feed the IVE model, information on the vehicle technology, emission factors, driving behavior in the studied region, fleet composition, altitude, and meteorological conditions were provided [27].

The IVE model uses vehicle-specific power (VSP) and engine stress to take into account the influence of driving patterns in the emission rate. The VSP is defined as the power demand on the engine per unit vehicle mass and can be calculated from the below equation [43]:

$$
\begin{aligned}
\mathrm{VSP}= & v *[1.1 a+9.81(\operatorname{atan}(\sin (\text { grade })))+0.132] \\
& +.000302 v^{3}
\end{aligned}
$$

where $v$ is the vehicle velocity, $a$ is the vehicle acceleration, and grade is the road slope. The following equation shows how to estimate engine stress:

Engine Stress $=$ RPM Index

$$
+\left(0.08 \frac{\text { ton }}{\mathrm{kW}}\right) * \text { Preave Power }
$$

Preave Power $=$ Average $\left(\operatorname{VSP}_{t=-5}\right.$ to $\left.-25 s\right)\left(\frac{\mathrm{kW}}{\text { ton }}\right)$

RPM Index $=\frac{\text { Velocity }_{t=0}}{\text { Speed Divider }}$

There are 60 bins made from combinations of three stress categories and 20 VSP categories.

In this study, the base emission rates in the IVE database for each vehicle technology were used in order to calculate the fleet average emission rates. The driving pattern developed by Fotouhi and Montazeri [44] for Tehran was used to calculate the bin distribution of different facility types. The driving pattern data of motorcycles was collected using a set of GPS probe measurements on 
Fig. 2 Cutting lines used to locate traffic counting stations over Tehran

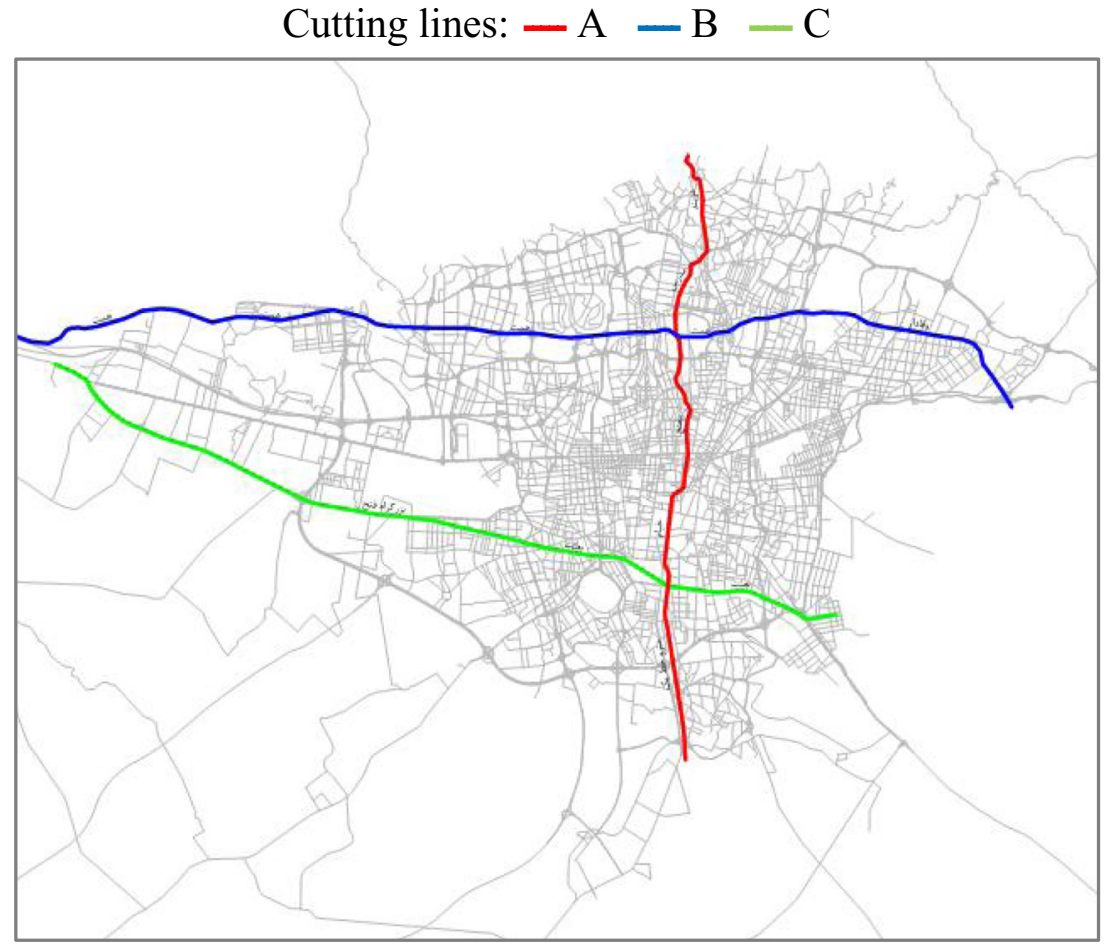

motorcycles. Three facility types were used in this study: highway, arterial, and residential roads. The average emission factors for $\mathrm{CO}_{2}, \mathrm{CO}, \mathrm{NO}_{x}, \mathrm{VOC}, \mathrm{SO}_{x}$, and PM emissions for diesel-, gasoline-, and natural gas-fueled vehicles were calculated for the three road types and three road grades of uphill, downhill, and flat.

\subsection{Data Collection}

\subsubsection{Traffic Data}

Generally, in order to calculate the emission rates, activity data is inferred from fuel consumption data or traffic data. In this study, both methods are used. Traffic activity data is vehicle kilometers traveled (VKT), and it refers to the total distance traveled by vehicles within the inventory domain or study area. In general, direct traffic-based estimates provide a better representation of vehicle activity than fuel consumption statistics [45].

In this study, link-based activity data has been obtained from the EMME/2 travel demand model (TDM), which was conducted by the Tehran Comprehensive Transportation and Traffic Study (TCTTS) Company, one of the leading consulting groups in Iran with expertise in the area of urban transportation planning and engineering. The TCTTS Company calculated the traffic volume in seven vehicle categories for each Tehran road using a four-stage traffic model based on the EMME/2 TDM and calibrated it by measurement data.
Fig. 3 Contribution of different vehicle types on total kilometer travels in the morning rush hour

\begin{tabular}{|c|c|c|}
\hline Passenger Car & Pickup & Minibus \\
\hline$\square$ Tehran municipal bus $\square$ Private sector bus & Truck & Motorcycle \\
\hline
\end{tabular}

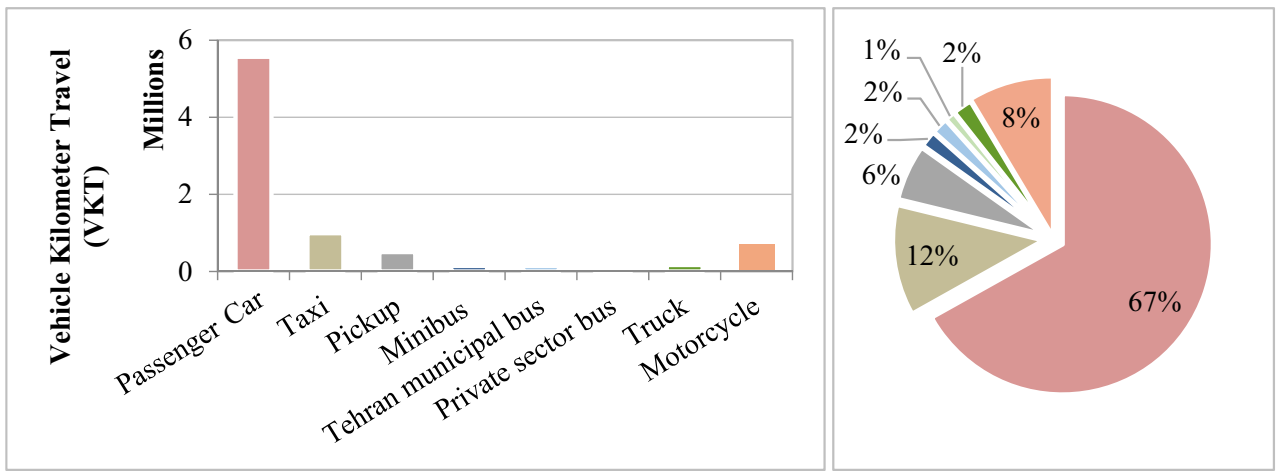


Fig. 4 Distribution of total kilometer travel over Tehran in the morning rush hour

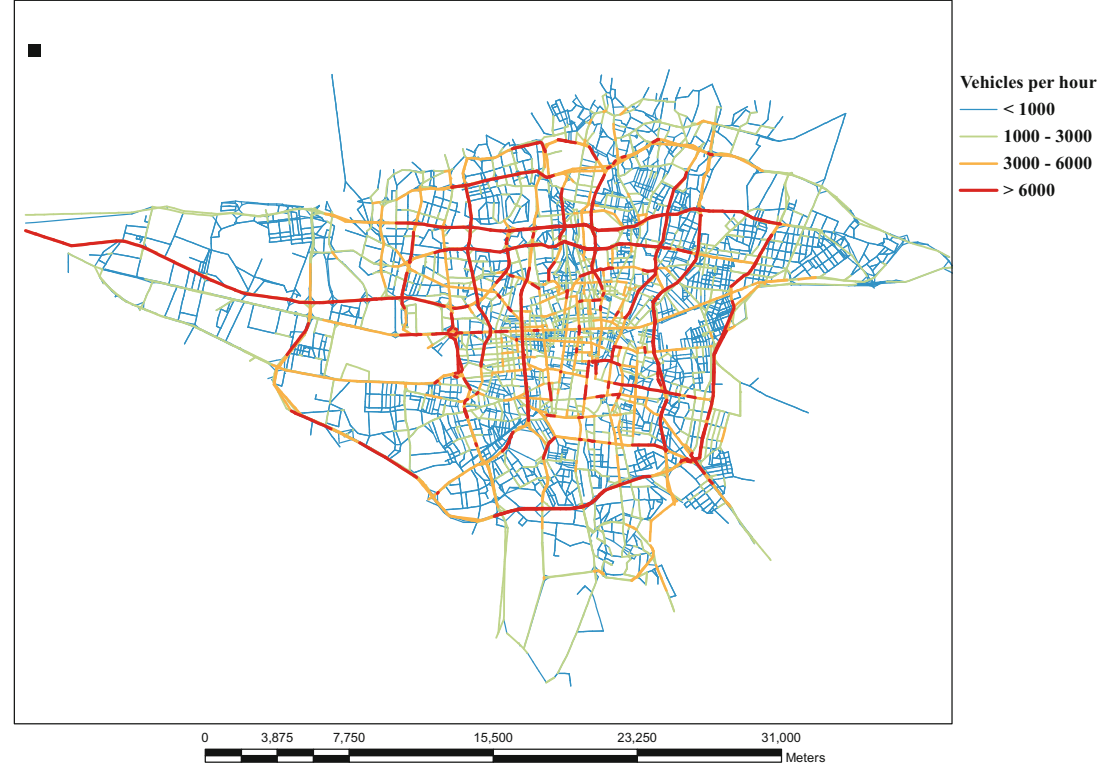

The TDM has a very detailed representation of the transport network. Therefore, it is suitable for link-based emission estimation. The spatial resolution can be set at the link level in order to find streets with high emission levels. Outputs from the TDM provide estimated travel times and traffic flows for all of the 17,441 individual links in Tehran, as well as average speeds, volumecapacity ratios, speed limits, and so on for each type of vehicle with different technologies [46].

The TDM model was calibrated by the TCTTS Company using about 400 traffic counting stations all over the Tehran area during three successive weekdays from Monday to Wednesday each year. Intersections of the three cutting lines and streets are the locations of these traffic counting stations as shown in Fig. 2. Vehicle volumes are counted by thousands of observed vehicles and are reported every $15 \mathrm{~min}$ for every traffic count and also for each of the seven vehicle categories.

Since the Tehran transport model provides link-based traffic activity data on the morning rush hour (7:30-8:30 AM), the emission inventory temporal resolution is $1 \mathrm{~h}$. The data is from 2013; therefore, the emission estimation is for this year.

The total VKT obtained from the TDM model is illustrated in Fig. 3. The contribution of different vehicle categories to total VKT in Tehran in the morning rush hour of a sample day in April 2013 is shown. The total survey distance traveled in Tehran morning rush hour is 8.38 million km with $67 \%$ of that being from personal light-duty vehicles. Taxis, motorcycles,
Table 1 Classification of road types given by the TDM into IVE-considered facility types

\begin{tabular}{llc}
\hline Road type in TDM & $\begin{array}{l}\text { Road type considered } \\
\text { for emission inventory }\end{array}$ & $\begin{array}{l}\text { Road type } \\
\text { share in Tehran }\end{array}$ \\
\hline $\begin{array}{l}\text { Freeway } \\
\text { Urban freeway }\end{array}$ & Freeway & $17 \%$ \\
Expressway & & \\
Urban expressway & & \\
2-Lane road & & \\
4-Lane road & & $33 \%$ \\
Sidetrack & & \\
Primary arterial & Arterial & \\
Secondary arterial & & $50 \%$ \\
Ramp & & \\
Collector & Residential & \\
Local street & &
\end{tabular}


Fig. 5 Total number of registered vehicles in Tehran since 2005

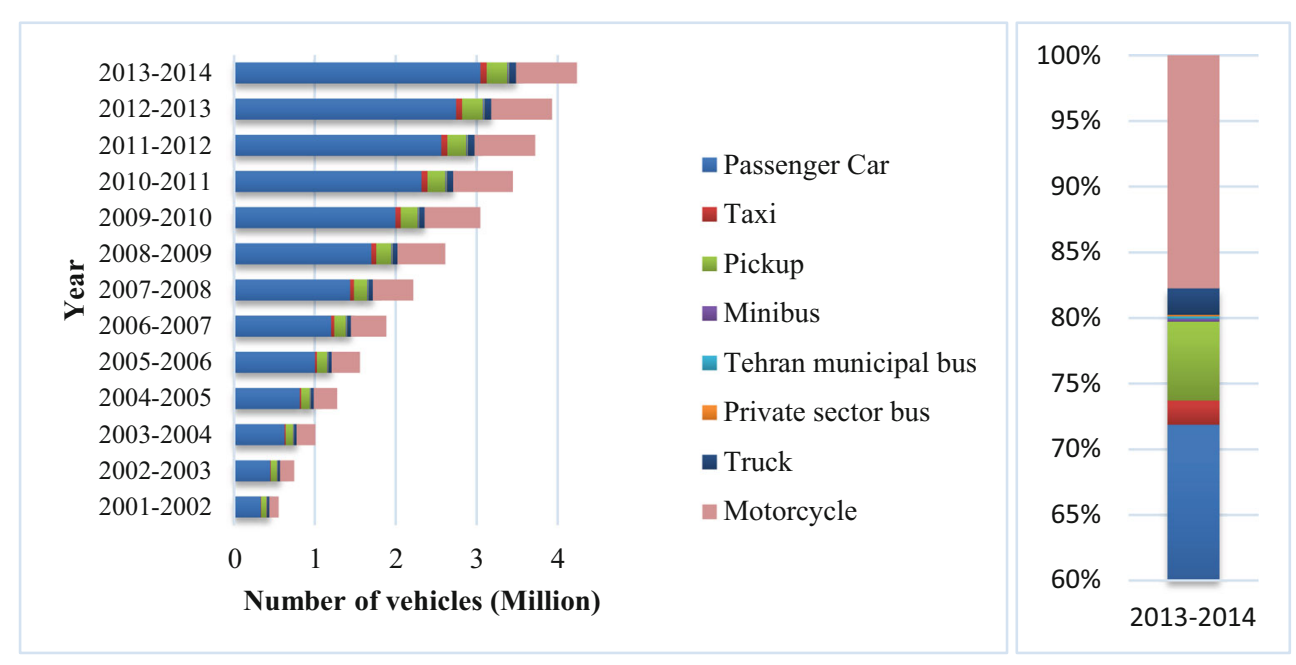

pickups, minibuses, municipality buses, private sector buses, and trucks contribute to $12,8,6,2,2,1$, and $2 \%$, respectively. The distribution of kilometers traveled by all vehicle types in Tehran is shown in Fig. 4. In the odd-even traffic restriction region, VKT is mainly contributed to by motorcycles, taxis, and other public transportation vehicles. Outside this region, passenger cars are the greatest contributors to VKT.

Traffic regulations restrict the operation of diesel trucks during the day in the city of Tehran. As such, in the morning rush hour of Tehran, truck traffic is observed only on the outskirts of the city where intercity highways exist.

Twelve types of roads in the Tehran traffic model are classified into three types, namely, freeway, arterial, and residential roads, based on the characteristics of the link, number of lanes, and speed limits, as shown in Table 1. Table 1 also shows the fraction of Tehran roads in each class, which sums up to $5000 \mathrm{~km}$. In the traffic model, each link (between two nodes) is also classified based on the road slope, namely, flat, uphill, and downhill roads. Flat roads are $50 \%$ (by length) of the total roads, uphill and downhill roads are each $21 \%$ of the total roads, and the slopes of $5 \%$ of the roads are unknown.

\subsubsection{Tehran Vehicle Fleet}

The Tehran TDM model only distinguishes between eight vehicle types. Hence, in order to correspond with traffic data, vehicles were classified into eight categories in this study, including passenger car, taxi, motorcycle, pickup, minibus, municipality bus, private sector bus, and truck.

The IVE model can distinguish between 1372 predefined vehicle technologies and an additional 45 undefined vehicle technologies which are categorized based on the vehicle size, fuel type, vehicle use, fuel delivery system, evaporative emission control system, and exhaust emission control system/ emission certification standard levels [47]. The Tehran fleet composition for each of eight categories mentioned above was classified into terms of the IVE vehicle technologies using Tehran vehicle data obtained from car registration information, which was provided by the traffic police department of Iran.

Figure 5 shows the total number of registered vehicles in Tehran from 2001 to 2014. As can be seen from this figure, the vehicle population in Tehran has grown rapidly, and the total number of registered vehicles for the city of Tehran has increased more than eightfold in the span of
Fig. 6 Tehran vehicle fleet age distribution

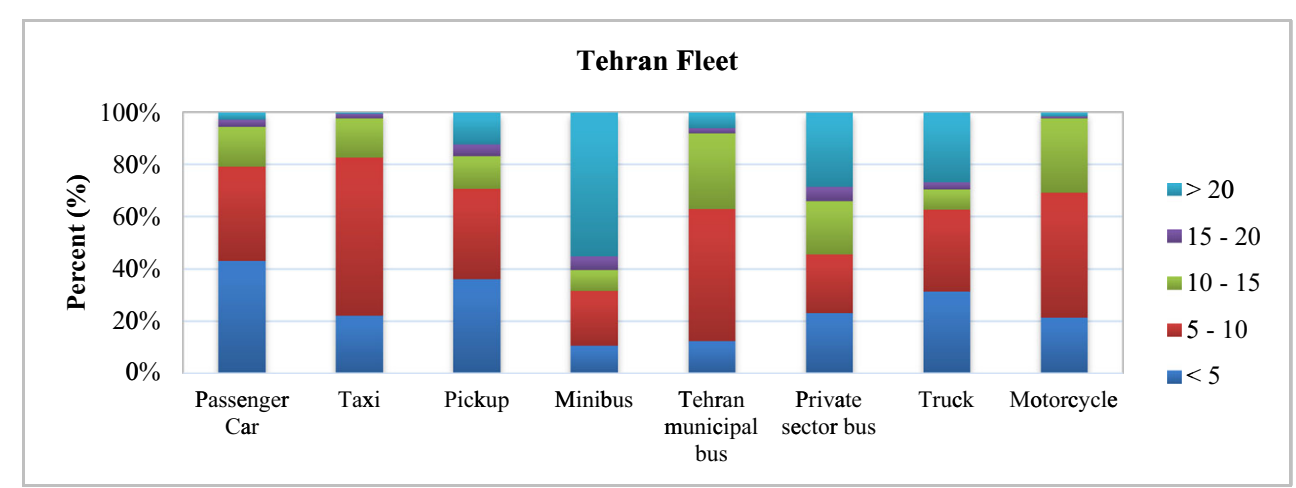


Table 2 Vehicle emission standard implementation in Iran

\begin{tabular}{lll}
\hline EURO standards & $\begin{array}{l}\text { Year of } \\
\text { implementation } \\
\text { in Iran }\end{array}$ & $\begin{array}{l}\text { Year of } \\
\text { implementation } \\
\text { in Europe }\end{array}$ \\
\hline $83 / 351 /$ EEC & 2000 & 1983 \\
$88 / 76 /$ EEC & 2003 & 1988 \\
EURO 1 & 2003 & 1992 \\
EURO 1 & - & 1993 \\
EURO 2 & 2005 & 1996 \\
EURO 2 & 2005 & 1998 \\
EURO 3 & & 2000 \\
EURO 4 & 2014 & 2005 \\
EURO 5 & & 2009 \\
EURO 6 & & 2014 \\
\hline
\end{tabular}

13 years. Today, there are about 4.24 million registered vehicles in Tehran with $71.9 \%$ of that being personal light-duty vehicles and $18 \%$ motorcycles. The rest of the fleet is composed of taxis, buses, minibuses, pickups, and trucks.

Vehicle age data were extracted from the year of production and were used to determine the vehicle technology and VKT. The technology distribution for each vehicle category was determined using each vehicle specification such as type, year of production, engine volume, and emission standard. [48] The distribution of different types of vehicles in various age intervals is shown in Fig. 6. This figure shows that about $43 \%$ of passenger cars are less than 5 years old, $36 \%$ of them are between 5 and 10 years old, and the rest of them are older than 10 years. The percentages of carburetor-equipped vehicles are 9.37, 4.76, and $22.29 \%$ in passenger cars, taxis, and pickups, respectively.

As vehicle emission regulations have been implemented in different years, vehicle age data were used accordingly to assign the emission certification levels of various vehicles, which in turn were used to determine the emission levels in the IVE model. Iranian national standard levels follow the European Union definitions of the certification levels. Table 2 shows the timeline of implementation of various European emission certification standards in Iran. Based on the vehicle registration data and emission certification implementations, Fig. 7 illustrates the fraction of each emission standard level in the total fleet composition.

The national Iranian light-duty vehicle fleet consists of more than $93 \%$ gasoline-only vehicles. The rest of the fleet is composed of dual-fueled gasoline-natural gas vehicles. No emission standards were implemented before 2000 in Iran.

The Tehran taxi fleet is similar to the light-duty passenger vehicle fleet with the exception of higher kilometers traveled. Most of the dual-fueled gasoline-natural gas vehicles belong to the Tehran taxi fleet. On average, each taxi travels 6-8 times more than a privately owned lightduty vehicle.

Motorcycles compose $18 \%$ of the total Tehran fleet. The motorcycle fleet has four-stroke, spark-ignited, gasoline-fueled, carburetor fueling system engines with no exhaust after-treatment system. Approximately, more than $90 \%$ of motorcycles in Tehran have single-cylinder
Fig. 7 Tehran vehicle fleet emission standard distribution

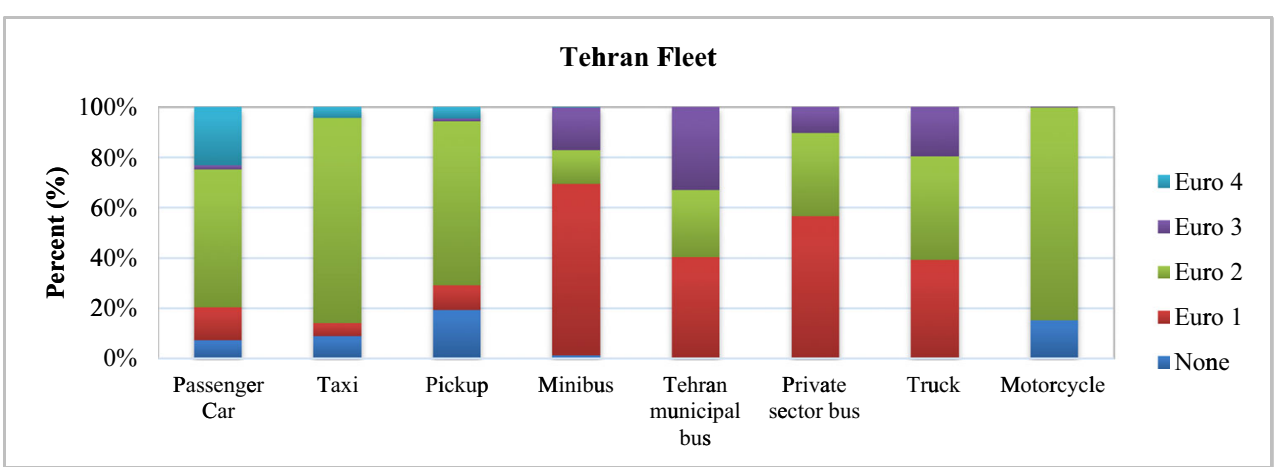


Table 3 Total criteria pollutant emission over Tehran in the morning rush hour

\begin{tabular}{lrr}
\hline Total emission & & \\
\hline & $\mathrm{kg} / \mathrm{h}$ & $\%$ \\
\hline $\mathrm{CO}$ & 87548.5 & 81.05 \\
$\mathrm{NO}_{x}$ & 7038.0 & 6.52 \\
$\mathrm{VOC}$ & 12004.8 & 11.11 \\
$\mathrm{SO}_{x}$ & 413.3 & 0.38 \\
$\mathrm{PM}$ & 1015.8 & 0.94 \\
\hline
\end{tabular}

$125-\mathrm{cm}^{3}$ engines. The rest of the motorcycles mostly have single-cylinder engines with a displacement volume of 180,200 , or $250 \mathrm{~cm}^{3}$.

\section{Results and Discussion}

In this section, the total emission estimates obtained for the morning rush hour in 2012 are presented and analyzed for each different vehicle group. The average emission rates are calculated for each vehicle category driving in different facility types using the IVE model, and they are multiplied by the traffic activity data to estimate pollutant emissions throughout Tehran. On the basis of this methodology, emissions are estimated for criteria pollutants at each link and are analyzed separately for vehicle groups.

The calculated emissions of Tehran motor vehicles for the morning rush hour are 87.5, 7, 12, 0.4, and 1 ton/h for $\mathrm{CO}, \mathrm{NO}_{x}, \mathrm{VOC}, \mathrm{SO}_{x}$, and $\mathrm{PM}$, respectively (Table 3). From a general analysis, it is found that the major contributor to emissions by weight is carbon monoxide, which is around $81 \%$ of the total emissions. The rest of the emissions are mainly composed by the VOCs and $\mathrm{NO}_{x}$ at almost 11.11 and $6.52 \%$, leaving the remaining distributed between $\mathrm{PM}$ and $\mathrm{SO}_{x}$.

Figure 8 presents the contribution of passenger cars, taxis, motorcycles, pickups, minibuses, Tehran municipal buses, private sector buses, and trucks to the total $\mathrm{CO}, \mathrm{NO}_{x}, \mathrm{VOC}, \mathrm{SO}_{x}$, and PM emissions. With the exception of PM emissions, which are produced mostly by motorcycles and medium and heavy-
Fig. 8 Contribution of different vehicle types on total $\mathbf{a} \mathrm{CO}, \mathbf{b}$ $\mathrm{NO}_{x}, \mathbf{c} \mathrm{VOC}, \mathbf{d} \mathrm{PM}$, and e $\mathrm{SO}_{x}$ emissions in the morning rush hour

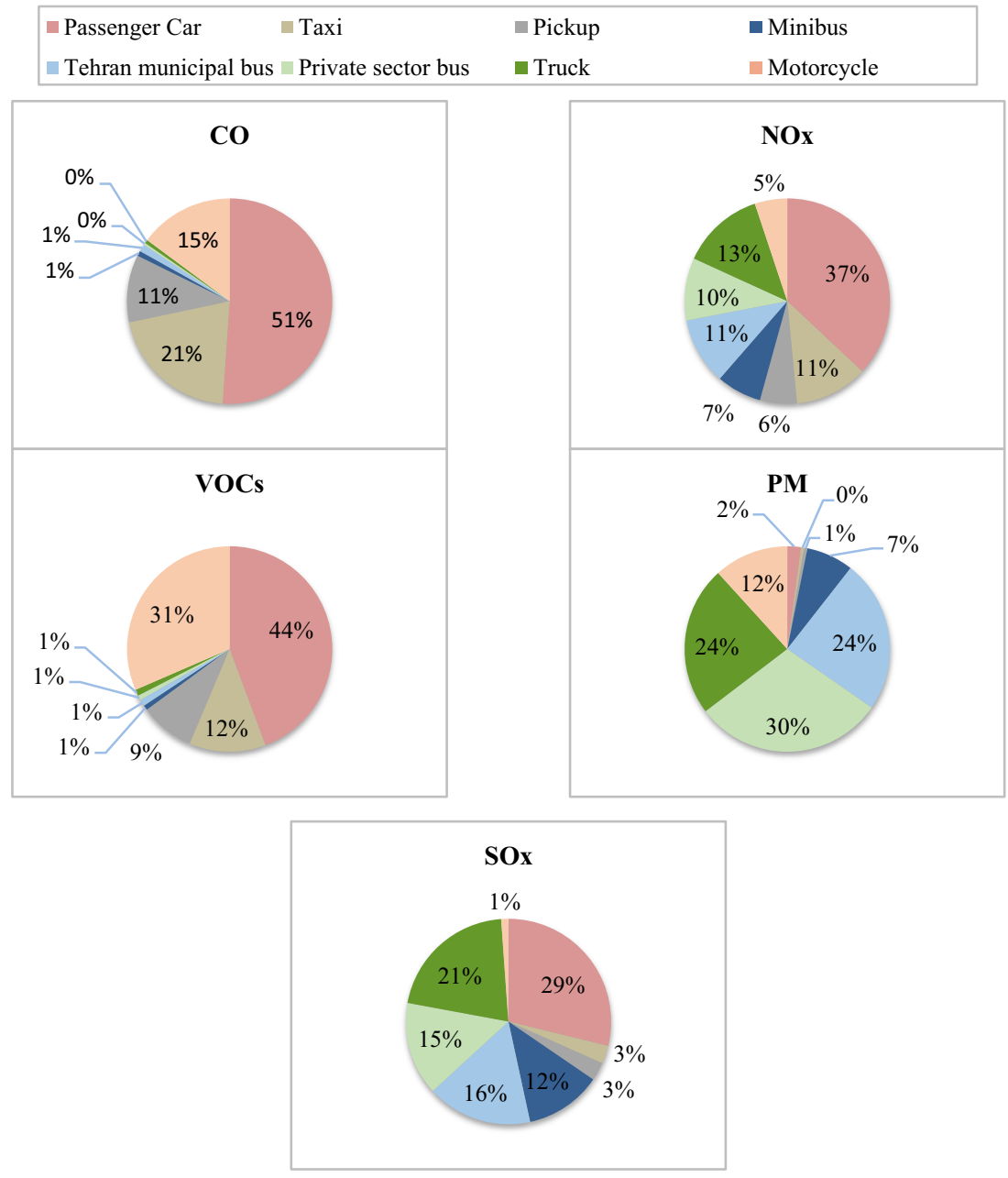




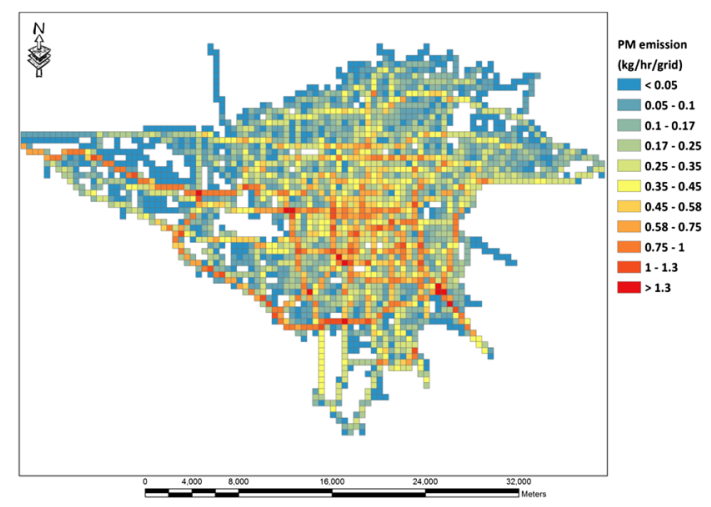

(a)

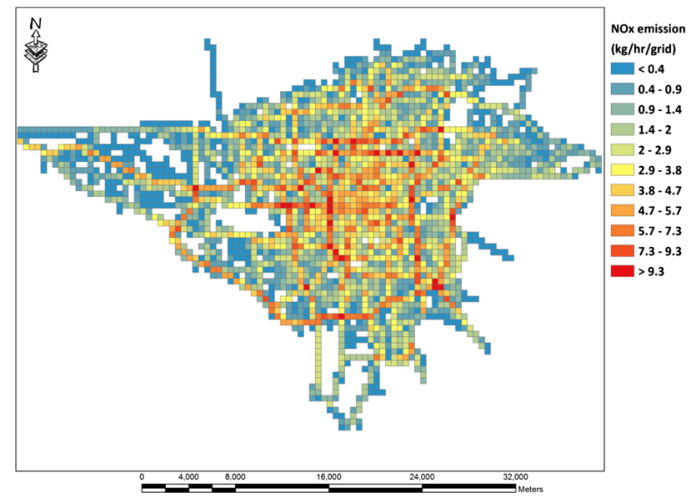

(b)

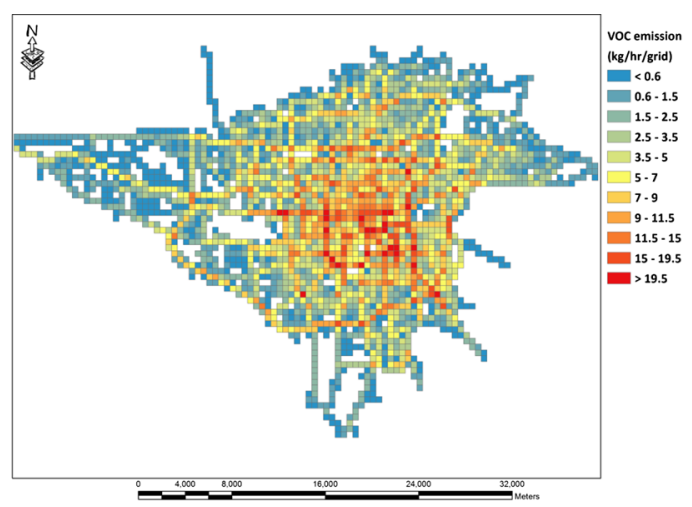

(c)

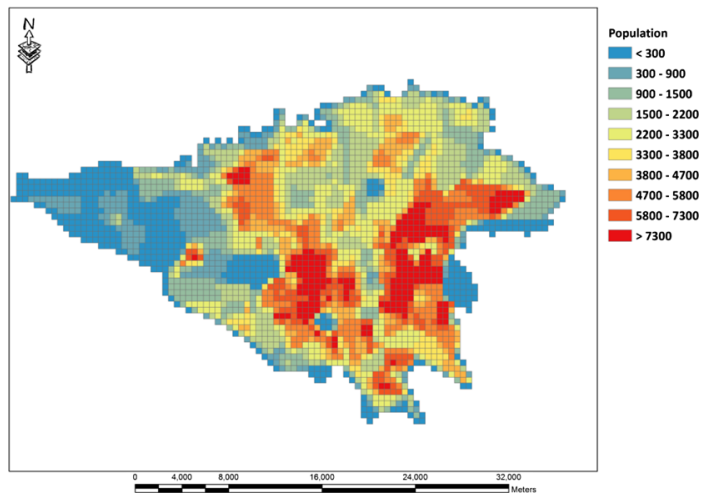

(d)

Fig. 9 Distribution of $\mathbf{a} \mathrm{PM}, \mathbf{b} \mathrm{NO}_{x}$, and $\mathbf{c}$ VOC emissions in the morning rush hour and $\mathbf{d}$ population over Tehran

duty vehicles, the rest of the emissions are produced by passenger cars.

The central zone of Tehran is restricted by traffic law so that only 80,000 passenger cars are allowed in this zone at a time. The rest of the fleet consists of taxis and motorcycles. The low technology levels of motorcycles with air-cooled low-compression ratio and carburetor fuel supply system have caused the high contribution from motorcycles to $\mathrm{CO}, \mathrm{VOC}$, and $\mathrm{PM}$ emissions.

\subsection{Spatial Analysis of Emissions}

The spatial distribution of pollutant emissions due to urban transportation for a morning rush hour in 2013 is shown in Fig. 9. The emissions have been gridded with a $0.5-\mathrm{km}$ grid resolution for air quality modeling.

Analyzing the distribution of aggregated emission of pollutants shows that emissions are mostly higher in central zones due to the high traffic rate of passenger cars, taxis, motorcycles, and buses. However, trucks are not allowed to enter residential areas of Tehran during the day, which leads to a considerable level of truckrelated emission on suburban roads around Tehran and entrance ways to Tehran.
The emission patterns are consistent with transportation networks. As shown in Fig. 9, VOC emissions are mostly concentrated in the central part of Tehran, which follows the total traffic pattern of passenger cars, taxis, pickups, and motorcycles with more concentration in the central commercial part of Tehran, where motorcycles are most concentrated in the morning rush hour. $\mathrm{NO}_{x}$ emission is more concentrated in the parts of Tehran containing entrance routes to Tehran because of the considerable contribution of medium and heavy-duty vehicles in $\mathrm{NO}_{x}$ emissions. It is possible to see that the high emission levels of PM are more related to the high traffic volume of motorcycles and medium and heavyduty vehicles, which includes the central commercial part of Tehran in the main, odd-even traffic restriction regions, and suburban routes of Tehran.

\subsection{Temporal Profiles}

Traffic volume of different vehicle categories from $6 \mathrm{AM}$ to $8 \mathrm{PM}$ are shown in Fig. 10. The temporal profiles were obtained from traffic data counted by the TCTTS Company at traffic counting stations for the city 
Fig. 10 Traffic volume for each vehicle category from $6 \mathrm{AM}$ to 8 PM based on counting data (left vertical axis for solid lines and right vertical axis for dashed lines)

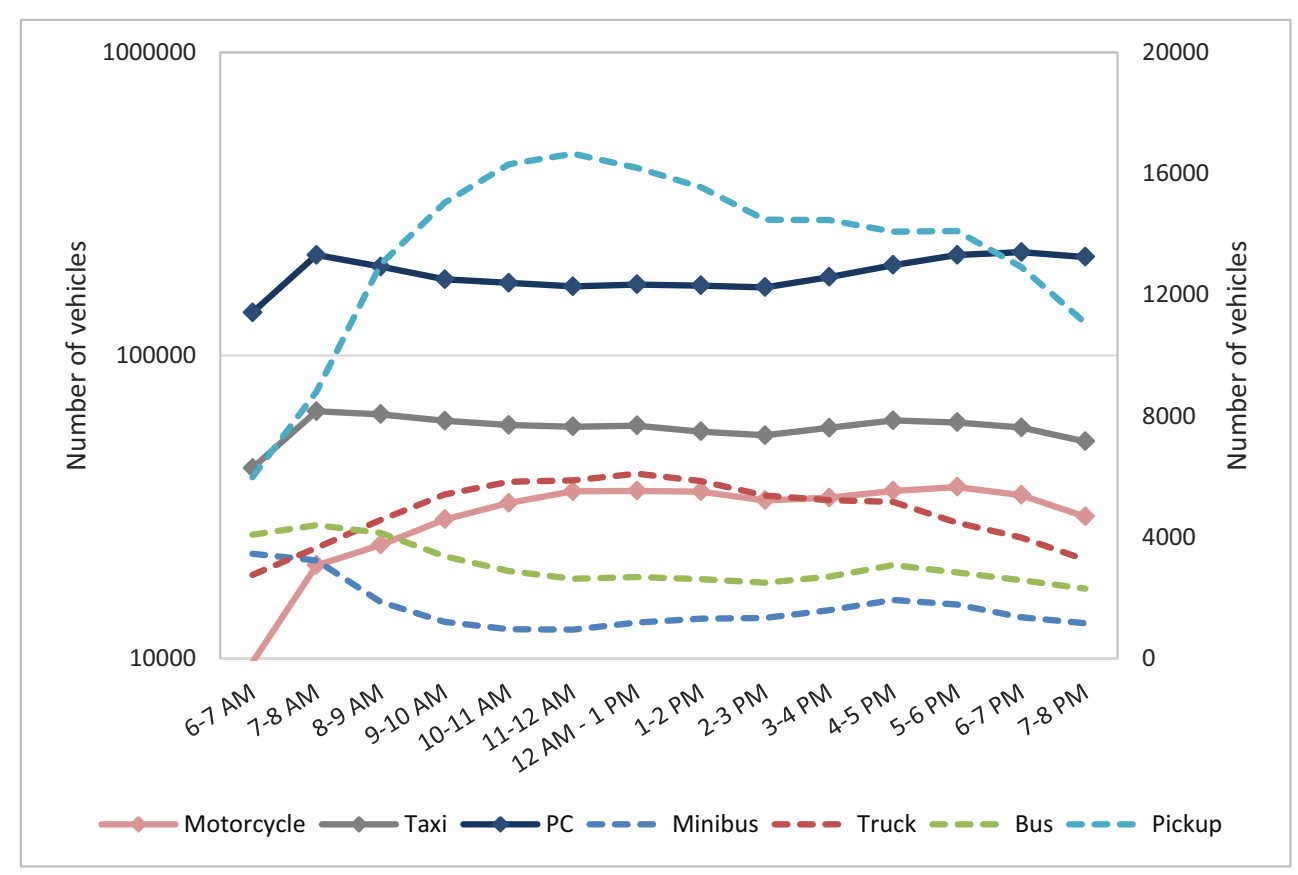

of Tehran in the year 2013. Counting stations are shown using $\mathrm{A}$ and $\mathrm{B}$ cutting lines in Fig. 2.

Higher traffic flows for passenger cars are found during morning (7-8 AM) and evening rush hours (5$8 \mathrm{PM})$. Approximately, the same trend is seen for taxis and minibuses plus buses, with more traffic volume in the morning rush hour. The hourly traffic volume of motorcycles shows two peak periods from 11 AM to $1 \mathrm{PM}$ and from $4 \mathrm{PM}$ to $7 \mathrm{PM}$. The traffic volume for pickups and trucks shows the same behavior, with traffic volume increasing in the morning, having a maximum from $10 \mathrm{AM}$ to $2 \mathrm{PM}$, and then decreasing until 8 PM.

\section{Emission Inventory Evaluation Using Fuel Consumption Data}

A comparison of overall emission rates of emissions of $\mathrm{CO}_{2}$, $\mathrm{CO}$, and VOCs with total fuel consumption of Tehran for transportation sector is conducted. This uses the carbon balance method (Eq. 5) that was used to calculate the fuel consumption of different types of gasoline-fueled vehicles.

$\mathrm{FC}=\frac{1.154}{\rho} \times\left\{(0.866 \times \mathrm{VOC})+(0.429 \times \mathrm{CO})+\left(0.273 \times \mathrm{CO}_{2}\right)\right\}$

In Eq. 5, FC is the fuel consumption in liters and $\rho$ is the density of gasoline, which is assumed to be $0.749 \mathrm{~g} /$ $\mathrm{cm}^{3}$. VOC, $\mathrm{CO}$, and $\mathrm{CO}_{2}$ are in kilograms from the emission inventory. The monthly gasoline consumption only for gasoline-fueled vehicles from the seven categories of the Tehran fleet is calculated using a temporal traffic profile. Typical monthly gasoline sales data for Tehran and its suburbs were obtained from National Iranian Oil Refining \& Distribution Company [49]. A reasonable agreement is seen between gasoline consumption calculated by emission inventory and gasoline sales data. The calculated gasoline consumption from the emission inventory is 9.72 million $\mathrm{L}$ on a working day, while gasoline sales data
Table 4 Share of carburetorequipped vehicles in total emission for different types of pollutants (percent)

\begin{tabular}{lrrrrrlr}
\hline & $\mathrm{CO}$ & $\mathrm{VOC}$ & $\mathrm{NO}_{x}$ & $\mathrm{SO}_{x}$ & $\mathrm{PM}$ & $\begin{array}{l}\text { Share of carburetor- } \\
\text { equipped vehicles in total } \\
\text { emission }\end{array}$ & $\begin{array}{l}\text { Share of carburetor- } \\
\text { equipped vehicles in total } \\
\text { fleet }\end{array}$ \\
\hline PCs & 51.7 & 57.0 & 35.5 & 14.4 & 22.8 & 51.3 & 9.4 \\
Pickups & 60.2 & 74.1 & 50.7 & 32.2 & 20.7 & 61.1 & 22.2 \\
Taxis & 14.1 & 24.0 & 11.5 & 14.8 & 9.0 & 14.7 & 4.7 \\
\hline
\end{tabular}


Table 5 Specification of clean and moderate fuels

\begin{tabular}{lll}
\hline & Gasoline: & Diesel: \\
\hline Clean fuel & Overall $=$ clean $/$ premixed & Overall = clean \\
& Sulfur $(\mathrm{S})=$ low $(50 \mathrm{ppm})$ & Sulfur $(\mathrm{S})=$ low $(50 \mathrm{ppm})$ \\
& Lead $(\mathrm{Pb})=$ none & \\
& Benzene $=$ moderate $(1.5 \%)$ & \\
& Oxygenate $=2.5 \%$ & \\
Overall $=$ moderate $/$ premixed & Overall $=$ moderate \\
Sulfur $(\mathrm{S})=$ moderate $(300 \mathrm{ppm})$ & Sulfur $(\mathrm{S})=$ high $(5000 \mathrm{ppm})$ \\
& Lead $(\mathrm{Pb})=$ none & \\
Benzene $=$ moderate $(1.5 \%)$ & \\
& Oxygenate $=0 \%$ & \\
\hline
\end{tabular}

range between 7.37 and 9.09 million $\mathrm{L}$ for Tehran and between 10.62 and 13.21 million $\mathrm{L}$ for Tehran plus its suburbs in difference months of the year. The calculated fuel consumption is higher than Tehran gasoline sales and lower than Tehran plus its suburbs gasoline sales data, because during the day, many vehicles travel to Tehran from its suburbs.

\section{Impact of Fleet Characteristics and Fuel Quality on Tehran Emission}

\subsection{Carburetor-Equipped Passenger Cars, Taxis, and Pickups}

The percentages of carburetor-equipped vehicles are 9.4, 4.7, and $22.1 \%$ in passenger cars, taxis, and pickups, respectively, according to car registration information.

The share of carburetor-equipped passenger cars, taxis, and pickups for different types of pollutants is given in Table 4. Although only $9.4 \%$ of personal cars are carburetor-equipped, the emission results show that $51.3 \%$ of total emissions of personal cars in Tehran are emitted from these types of vehicles. Therefore, carburetor-equipped personal cars are emitting 400 tons per day of pollutants in Tehran. About $22 \%$ of pickups in Tehran are equipped with carburetor systems, with the share of $60.2,74.1,50.7,32.2$, and $20.7 \%$ in total $\mathrm{CO}$, VOCs, $\mathrm{NO}_{x}, \mathrm{SO}_{x}$, and $\mathrm{PM}$ emissions from pickups, respectively.

From this section, it can be concluded that replacing carburetor-equipped cars with Euro IV vehicles will reduce the air pollution in Tehran enormously.

\subsection{Investigation of the Effect of Fuel Quality in Vehicle Emissions}

In order to investigate the fuel influence in emissions, two types of fuel are considered: moderate fuel (which currently is consumed in Tehran) and clean fuel. Table 5 shows the specifications for these fuels. Moderate/premixed selection for overall fuel quality will not have an effect on emissions, and clean fuel will improve emissions of four-stroke gasoline vehicles. The main difference between these fuels is the quantity of sulfur content.

Analyzing the emission results showed that by improving the fuel quality, total $\mathrm{CO}, \mathrm{VOC}, \mathrm{NO}_{x}, \mathrm{SO}_{x}$, and $\mathrm{PM}$ emissions of vehicles will be reduced by $20.3,14.4,3.2,93.2$, and $3 \%$, respectively, during the morning rush hour.

\section{Conclusion}

An emission inventory for Tehran was developed for mobile sources using emission rates calculated by the IVE model. The vehicle technology and age data were obtained from car registration information from the traffic police department of Iran, and link-based activity data has been obtained from the EMME/2 TDM conducted by the TCTTS Company. Tehran traffic data were multiplied by emission rates derived from the IVE model in order to estimate pollutant emissions at the link level. The contribution of each vehicle type to total mobile source emissions and the distribution of emissions in different areas of Tehran were examined. The developed emission inventory was evaluated using gasoline sales data. It was concluded that

1. There are 4.2 million registered vehicles in Tehran, with $72 \%$ of these vehicles being registered as personal cars that consist only of gasoline-fueled light-duty vehicles and a small share of CNG-fueled vehicles. Motorcycles are $18 \%$ of the total vehicles in Tehran, and the remaining $10 \%$ consists of taxis, buses, minibuses, pickups, and trucks.

2. The total survey distance in Tehran at the morning rush hour is 8.38 million $\mathrm{km}$, of which personal cars had the largest share (67\%). Taxis, motorcycles, pickups, minibuses, buses, and trucks contribute $12,8,6,2,3$, and $2 \%$ of the total kilometers traveled, respectively. 
3. The estimated emissions from motor vehicles in Tehran for the morning rush hour are 87.5, 7, 12, 0.40, and 1 tons/ $\mathrm{h}$, for $\mathrm{CO}, \mathrm{NO}_{x}, \mathrm{VOC}, \mathrm{SO}_{x}$, and $\mathrm{PM}$, respectively.

4. Motorcycles contribute to $15 \%$ of total CO, $31 \%$ of total VOC, and $12 \%$ of total PM emissions. This makes the fleet of motorcycles one of the main concerns for Tehran air quality which is mostly associated with poor air-fuel ratio adjustment of carburetor-type engines and lowefficiency combustion.

5. Medium and heavy-duty vehicles (minibuses, buses, and trucks) are only $2.4 \%$ of the Tehran fleet, but contribute more than 41,64 , and $85 \%$ of the $\mathrm{NO}_{x}, \mathrm{SO}_{x}$, and $\mathrm{PM}$ emissions, respectively.

6. Analyzing the distribution of the aggregated emission of pollutants shows that the emissions are mostly higher in central zones because of the high traffic rate of personal cars, taxis, motorcycles, and buses.

7. Although only $9.4 \%$ of personal cars are equipped with a carburetor, the emission results show that $51.3 \%$ of the total emissions from personal cars in Tehran are emitted from these types of vehicles.

8. By improving the fuel quality, the total $\mathrm{CO}, \mathrm{VOC}, \mathrm{NO}_{x}$, $\mathrm{SO}_{x}$, and $\mathrm{PM}$ emissions of vehicles during morning rush hour will be reduced by $20.3,14.4,3.2,93.2$, and $3 \%$, respectively.

Acknowledgments The contribution of Deputy Transportation of Tehran Municipality, Tehran Air Quality Control Co., and TCTTS for providing data to this study is acknowledged.

\section{References}

1. World-Bank,:Islamic Republic of Iran Cost Assessment of Environmental Degradation. 2005.

2. Cass, G.R., McRae, G.J.: Minimizing the cost of air pollution control. Env. Sci. Technol. 15(7), 748-757 (1981)

3. Houyoux, M.R., et al.: Emission inventory development and processing for the Seasonal Model for Regional Air Quality (SMRAQ) project. J. Geophys. Res. 105(D7), 9079-9090 (2000). Atmospheres (1984-2012)

4. Miller, C.A., et al.: Air emission inventories in North America: a critical assessment. J. Air Waste Manage. Assoc. 56(8), 1115-1129 (2006)

5. Pant, P., Harrison, R.M.: Estimation of the contribution of road traffic emissions to particulate matter concentrations from field measurements: a review. Atmos. Environ. 77, 78-97 (2013)

6. Franco, V., et al.: Road vehicle emission factors development: a review. Atmos. Environ. 70, 84-97 (2013)

7. Huai, T., et al.: Estimates of the emission rates of nitrous oxide from light-duty vehicles using different chassis dynamometer test cycles. Atmos. Environ. 38(38), 6621-6629 (2004)

8. Li, L., et al.: Exhaust and evaporative emissions from motorcycles fueled with ethanol gasoline blends. Sci. Total Environ. 502, 627631 (2015)

9. Li, T., Chen, X., Yan, Z.: Comparison of fine particles emissions of light-duty gasoline vehicles from chassis dynamometer tests and on-road measurements. Atmos. Environ. 68, 82-91 (2013)
10. Kousoulidou, M., et al.: Use of portable emissions measurement system (PEMS) for the development and validation of passenger car emission factors. Atmos. Environ. 64, 329-338 (2013)

11. Rubino, L., et al.: On-road emissions and fuel economy of light duty vehicles using PEMS: chase-testing experiment. (2008). SAE Technical Paper.

12. Yao, Z., et al.: On-road emission characteristics of VOCs from diesel trucks in Beijing. China. Atmos. Environ. 103, 87-93 (2015)

13. Huang, C., et al.: A PEMS study of the emissions of gaseous pollutants and ultrafine particles from gasoline- and diesel-fueled vehicles. Atmos. Environ. 77, 703-710 (2013)

14. Zhou, Y., et al.: Evaluating the emission status of light-duty gasoline vehicles and motorcycles in Macao with real-world remote sensing measurement. J. Environ. Sci. 26(11), 2240-2248 (2014)

15. Sánchez-Ccoyllo, O.R., et al.: Vehicular particulate matter emissions in road tunnels in Sao Paulo, Brazil. Environ. Monit. Assess. 149(1-4), 241-249 (2009)

16. Zhao, Y., Sadek, A.W.: Computationally-efficient approaches to integrating the MOVES emissions model with traffic simulators. Procedia Comput. Sci. 19, 882-887 (2013)

17. Wu, Y., Song, G., Yu, L.: Sensitive analysis of emission rates in MOVES for developing site-specific emission database. Transp. Res. Part D: Transp. Environ. 32, 193-206 (2014)

18. Wallace, H.W., et al.: Comparison of wintertime CO to NOx ratios to MOVES and MOBILE6.2 on-road emissions inventories. Atmos. Environ. 63, 289-297 (2012)

19. EPA. Environmental Protection Agency (EPA), MOVES model (2004): Available from: http://www.epa.gov/otaq/models/moves/.

20. EEA. European Environment Agency (EEA), COPERT (2002): Available from: http://www.emisia.com/copert.

21. Soylu, S.: Estimation of Turkish road transport emissions. Energy. Policy. 35(8), 4088-4094 (2007)

22. Kassomenos, P., Karakitsios, S., Papaloukas, C.: Estimation of daily traffic emissions in a South-European urban agglomeration during a workday. Evaluation of several "what if" scenarios. Sci. Total Environ. 370(2-3), 480-490 (2006)

23. Fameli, K., Assimakopoulos, V.: Development of a road transport emission inventory for Greece and the Greater Athens Area: effects of important parameters. Sci. Total Environ. 505, 770-786 (2015)

24. GUO, H., et al.: Evaluation of the International Vehicle Emission (IVE) model with on-road remote sensing measurements. J. Environ. Sci. 19(7), 818-826 (2007)

25. Zhang, Q., et al.: Air pollutant emissions from vehicles in China under various energy scenarios. Sci. Total Environ. 450, 250-258 (2013)

26. Wang, H., et al.: On-road vehicle emission inventory and its uncertainty analysis for Shanghai. China. Sci. Total Environ. 398(1), 6067 (2008)

27. Mishra, D., Goyal, P.: Estimation of vehicular emissions using dynamic emission factors: a case study of Delhi. India. Atmos. Environ. 98, 1-7 (2014)

28. Nagpure, A., Gurjar, B., Kumar, P.: Impact of altitude on emission rates of ozone precursors from gasoline-driven light-duty commercial vehicles. Atmos. Environ. 45(7), 1413-1417 (2011)

29. Kim Oanh, N.T., Thuy Phuong, M.T., Permadi, D.A.: Analysis of motorcycle fleet in Hanoi for estimation of air pollution emission and climate mitigation co-benefit of technology implementation. Atmos. Environ. 59, 438-448 (2012)

30. Shrestha, S.R., et al.: Analysis of the vehicle fleet in the Kathmandu Valley for estimation of environment and climate co-benefits of technology intrusions. Atmos. Environ. 81, 579-590 (2013)

31. Nesamani, K.: Estimation of automobile emissions and control strategies in India. Sci. Total Environ. 408(8), 1800-1811 (2010)

32. (JICA), J.I.C.A.: The Study on an integrated Master Plan for Air Pollution Control in The Greater Area in The Islamic Republic of Iran (1997). 
33. Coelho, M.C., et al.: Assessment of potential improvements on regional air quality modelling related with implementation of a detailed methodology for traffic emission estimation. Sci. Total Environ. 470, 127-137 (2014)

34. Cai, H., Xie, S.: Traffic-related air pollution modeling during the 2008 Beijing Olympic Games: the effects of an odd-even day traffic restriction scheme. Sci. Total Environ. 409(10), 1935-1948 (2011)

35. Borge, R., et al.: Comparison of road traffic emission models in Madrid (Spain). Atmos. Environ. 62, 461-471 (2012)

36. Ho, B.Q., Clappier, A.: Road traffic emission inventory for air quality modelling and to evaluate the abatement strategies: a case of Ho Chi minh city. Vietnam. Atmos. Environ. 45(21), 3584-3593 (2011)

37. Hassanzadeh, S., Hosseinibalam, F., Alizadeh, R.: Statistical models and time series forecasting of sulfur dioxide: a case study Tehran. Environ. Monit. Assess. 155(1-4), 149-155 (2009)

38. Ashrafi, K.: Determining of spatial distribution patterns and temporal trends of an air pollutant using proper orthogonal decomposition basis functions. Atmos. Environ. 47, 468-476 (2012)

39. Naddafi, K., et al.: Health impact assessment of air pollution in megacity of Tehran, Iran. Iran. J. Environ. Health Sci. Eng. 9(1), 1-7 (2012)

40. Bidokhti, A., Shariepour, Z.: Upper air meteorological conditions of acute air pollution episodes (case study: Tehran). J. Environ. Stud. 35(52), 1 (2010)
41. USGS: Landsat Climate Data Record (CDR) surface reflectance product guide. v 3.4. (2013).

42. Sohrabinia, M., Khorshiddoust, A.M.: Application of satellite data and GIS in studying air pollutants in Tehran. Habitat. Int. 31(2), 268-275 (2007)

43. Frey, H.C., Zhang, K., Rouphail, N.M.: Fuel use and emissions comparisons for alternative routes, time of day, road grade, and vehicles based on in-use measurements. Environ. Sci. Technol. 42(7), 2483-2489 (2008)

44. Fotouhi, A., Montazeri-Gh, M.: Tehran driving cycle development using the k-means clustering method. Scientia. Iran. 20(2), 286-293 (2013)

45. Villarreal, M.M.: From area-wide to link-based emission modeling. Development of a methodology for improving emission estimates of road transport in Guadalajara, Mexico. Technische Universität München (2010)

46. Oppenheim, N.: Urban travel demand modeling: from individual choices to general equilibrium. John Wiley and Sons (1995)

47. Shafie-Pour, M., Tavakoli, A.: On-road vehicle emissions forecast using IVE simulation model. Int. J. Env. Res. 7(2), 367-376 (2013)

48. Huo, H., et al.: Modeling vehicle emissions in different types of Chinese cities: importance of vehicle fleet and local features. Environ. Pollut. 159(10), 2954-2960 (2011)

49. NIORDC, National Iranian Oil Refining \& Distribution Company (2014): Available from: http://en.niordc.ir/index.aspx?siteid= 77 \&pageid $=536$. 